\title{
Analysis of critical drivers affecting implementation of agent technology in a manufacturing system
}

\author{
Om Ji Shukla ${ }^{1}$ - Abhijeet Joshi ${ }^{1} \cdot$ Gunjan Soni ${ }^{1} \cdot$ Rajesh Kumar $^{2}$
}

Received: 1 May 2017 / Accepted: 5 October 2018 / Published online: 10 October 2018

(c) The Author(s) 2018

\begin{abstract}
Technological advancement in the manufacturing system in current scenario is inevitable due to today's customer-driven and volatile nature of the market. Implementation of agent technology in a manufacturing system increases flexibility which handles uncertainty generated due to advance technology. Therefore, in this paper, the critical drivers affecting implementation of agent technology are identified and the relationships among them are analysed for a case study of a manufacturing system in an Indian steering wheel manufacturing company. Interpretive structural modelling (ISM) is used to provide binary relationships among identified critical drivers (CDs), while MICMAC approach describes sensitive analysis of driving and dependence behaviour of CDs. The classification of the drivers affecting agent technology and their relationships according to ISM-MICMAC approach provides importance to this study. A structural model is developed for providing rank to the identified critical drivers, and driving-dependent power diagram is presented for analysing the behaviour of different critical drivers with respect to others. The identification of the most influential CDs that lead to increase the effect of other drivers is the major finding of this study. Finally, the implication of this research for the industries is also described.
\end{abstract}

Keywords Agent technology (AT) $\cdot$ Interpretive structural modelling (ISM) $\cdot$ Manufacturing system $\cdot$ Critical drivers $(\mathrm{CDs}) \cdot$ MICMAC analysis

\section{Introduction}

A manufacturing system comprises the arrangement of manufacturing equipment in certain manner. It has a physical layout (job shop, flow shop, cellular system and project shop) tangibly, while production control operates on production philosophies intangibly. The important elements of a manufacturing system are material transfer, methods of information and energy which includes performance measures of the

Gunjan Soni

gunjan1980@gmail.com

Om Ji Shukla

om.mechanical@gmail.com

Abhijeet Joshi

abhijeet.joshi868@gmail.com

Rajesh Kumar

rkumar.ee@gmail.com

1 Department of Mechanical Engineering, Malaviya National Institute of Technology Jaipur, Jaipur, Rajasthan, India

2 Department of Electrical Engineering, Malaviya National Institute of Technology Jaipur, Jaipur, Rajasthan, India system (Chryssolouris 2006). Today's manufacturing environment is highly uncertain as well as continuously changing which is characterised by smaller life cycle of technologies, lesser lead time, better customised price of standard product, increased product quality and variety and extreme global competition. The researchers agree that the level of uncertainty will be growing continuously in the coming years (D'Souza and Williams 2000; Urtasun-Alonso et al. 2014). Prospectively, the manufacturing industries which are highly flexible will satisfy customer demand rapidly with continuous changing customer requirements (Winkler and Seebacher 2011). Hence, manufacturing systems must be much more flexible to changing product variety and production volume conditions (Zhang et al. 2003).

Recent economic growth shows that flexibility has played a significant role in manufacturing; therefore, many production systems consider flexibility as a main objective. Seebacher and Winkler (2014) developed a two-dimensional model for evaluation of manufacturing flexibility by analysing the performance of batch production systems. Narasimhan et al. (2004) presented conceptual model for examining the role of flexibility through flexibility competence 
and execution competence and a multistage data envelopment analysis of empirical data. Use of advance technology like highly automated machines and the new control logic approaches increase both flexibility and complexity of the manufacturing systems (Papakostas et al. 2011).

In today's world, the advancement of technology is not limited to one country; it has become global. Technological advancements generate complexities in the system, and uncertainty is inevitable consequence of these complexities (Shi and Daniels 2003). Every manufacturing industry wants to have a manufacturing system with modern production technologies to encounter the challenges of today's customer-driven and unpredictable market. The concept of agent technology is the most important and vibrant area of research. An agent is a software system that has autonomous, social, reactiveness and pro-activeness behaviour (Wooldridge 2002). A manufacturing system with agent technology is the most emerging manufacturing system that has such type of control strategies which can handle uncertainty and unforeseen situations in an efficient way by taking smart decisions. Therefore, the management of a company should identify and understand the critical drivers (CDs) of agent technology (AT) and their interrelationships in a manufacturing system for its successful adoption. In this paper, an ISM model for CDs of agent-based manufacturing system in an Indian steering wheel manufacturing company ' $\mathrm{S}$ ' is developed. The MICMAC analysis of the CDs is also presented in this article which indicates their driving and dependence power.

Further, remaining paper is organised as: "Literature review" section introduces the concept of agent technology in manufacturing systems along with critical drivers and brief review of ISM approach in various applications. The development of ISM methodology is discussed in "Development of ISM methodology for implementation of agent technology in manufacturing system" section. "Application of ISM methodology for the Indian steering wheel manufacturing company" section describes the application of ISM methodology in an Indian steering wheel manufacturing company. The MICMAC analysis is done in "MICMAC analysis" section, whereas "Finding and discussion" section describes the finding of this study and discussion. "Implications of the research" section discusses the implications of this research followed by conclusion in "Conclusion" section.

\section{Literature review}

This section presents an appropriate literature highlighting the importance of agent technology in manufacturing systems along with critical drivers to facilitate proper understanding of the interactions between the proposed drivers.

\section{The concept of agent technology in manufacturing systems}

Several research articles have widely discussed flowshop and job-shop problems in manufacturing systems by scheduling perspective. Babayan and He (2004) adopted agent technology-based cooperation in scheduling system to solve $n$-job three-stage flexible flow-shop scheduling problem. Weng and Fujimura (2010) provided solutions for dynamic flow-shop scheduling problem using multiagent feedbacks which collect real-time information and accordingly make decisions and work interactively. A hybrid flow-shop scheduling problem is solved by Yuewen et al. (2011) using multi-agent particle swarm optimisation. Rezki et al. (2016) presented an intelligent system based on multi-agents for complex process monitoring tasks such as detection, diagnosis, identification and reconfiguration in industrial systems.

Alotaibi et al. (2016) introduced two types of uncertainty: machines breakdown and dynamic job arrival into job-shop manufacturing system. Here, the authors proposed a multiagent-based decision-making and negotiation model to deal these uncertain events and solve dynamic bi-objective robustness for tardiness and energy in job-shop scheduling. Nouri et al. (2016) presented two NP hard problems simultaneously: robot routing problem and job-shop scheduling problem. This complex problem requires the use of agent technology. Therefore, the authors had proposed hybrid meta-heuristics based on clustered holonic multiagent model to solve the above complex problem. While Nouri et al. (2018) proposed hybrid meta-heuristic-based multi-agent model for solving flexible job-shop scheduling problem in which neighbourhood-based genetic algorithm (NGA) is used for global exploration of the search. Erol et al. (2012) proposed agent-based approach for real-time scheduling of machines and automated guided vehicles in production system. In this approach, the dynamic feasible schedules were generated through negotiation mechanisms between agents. Zhang and Wang (2016) considered reentrant manufacturing systems (RMSs) for analysing its production scheduling problems. A hierarchical collaborative system with agent technology had been developed by the authors to increase the efficiency of RMSs. Antzoulatos et al. (2017) presented an agent framework for industrial assembly systems in order to deal with frequent changing resources and its capabilities and product specifications.

In all the above research examples, the agent technology was used to deal with the complexities involved in the manufacturing systems. There are several key drivers that suggest the vital role of agents and agent technologies. Identification and description about critical drivers of agent technology is given in the following subsection. 


\section{Critical drivers of agent technology}

After scanning the plethora of literature related to multiagent systems, it may be pointed out that lack of evidence in recent literature suggests that the drivers or enablers of agent technology are yet to be discussed by the researchers. There are some authors who identified new technologies/ drivers to improve the efficiency of multi-agent systems in their articles, but only Luck et al. (2005) described these new technologies collectively as critical drivers of AT at one place. In this paper, seven technologies as CDs that can influence AT implementation in a manufacturing system are identified based on available literature and through brainstorming sessions with decision-makers which consist of both industry experts and academic experts. The description of CDs is as follows:

\section{Semantic web}

Berners-Lee et al. (2001) described semantic web as a developed version of the present web on which data are stored and structured in a way that it can be read by computers for the automatic processing in different applications. GarcíaSánchez et al. (2009) presented an ontology-based framework that integrates two technologies: 'intelligent agents' and 'semantic web services' for analysing benefits of their grouping. Hence, semantic web and agent technologies are intimately connected and enable to handle complex agentbased computing in manufacturing systems.

\section{Grid computing}

Foster and Kesselman (2004) referred the grid as a highperformance computing environment for supporting large distributed systems, information handling and knowledge management. Grid computing provides a virtual infrastructure to users with integrating data and computing resources for solving various types of problems (Blatecky 2002; Khan et al. 2017). The grid provides heterogeneous, distributed, unpredictable and autonomous resources. The flexibility is more generally the main benefit of grid computing (Garg et al. 2010). Yang et al. (2016) proposed a grid-based simulation environment for supporting parallel exploration on agent-based models with large parameter space and did extensive experiments which confirmed effectiveness, practicability and good scalability of this grid computing models.

\section{Peer-to-Peer computing}

Peer-to-Peer (P2P) computing provides an extensive sort of environments, systems and technologies that share distributed resources to accomplish a function in a decentralised way. Milojicic et al. (2002) surveyed the field of P2P computing systems and applications by analysing the design and implementation issues of P2P systems. This survey has helped the researchers by proposing potential benefits of $\mathrm{P} 2 \mathrm{P}$ systems as a strong alternative for the requirements of anonymity, scalability and fault resilience. Purvis et al. (2003) presented a multi-agent-based approach that supports multiple trader agents in electronic trading environments on multiple P2P computing platforms. Thus, P2P computing drives multi-agent technology in manufacturing systems.

\section{Ambient intelligence}

Ambient intelligence (AmI) is a popular research topic due its transparency, characteristics and intelligence. AmI can be described as an environment of large number of components which are independent and distributed interacting to each other and have characteristics of flexibility, autonomous, responsiveness, pro-activeness and so on which are the same as that of agents. The AmI considers numerous different aspects and technologies in manufacturing domain (Sanders and Tewkesbury 2009). Robinson et al. (2015) described the intelligent systems using AmI for monitoring energy consumption and knowledge management technologies in manufacturing system. Hence, AmI drives the agent technology in manufacturing systems.

\section{Self-systems and autonomic computing}

The computation systems which are able to cope themselves are called as self-systems that include some features such as self-organisation, self-management, self-configurable, self-awareness and self-repair. Autonomic computing is defined as self-organising behaviour of distributed computing resources adapting to uncertain changes. Barbosa et al. (2015) proposed a multi-agent-based adaptive holonic control architecture for distributed manufacturing systems, inspired by biological and evolutionary theories. A twodimensional self-organised mechanism inspired by hierarchical and heterarchical control approaches was designed to handle unexpected events and modifications. Madureira et al. (2014) presented a negotiation mechanism based on swarm intelligence for self-organised dynamic scheduling in manufacturing systems. Thus, self-systems give several application areas for agent technologies.

\section{Web services and service-oriented computing}

This technology provides a standard way for interoperation between different software applications running on different platforms. According to Booth et al. (2004), web services came out as the greatest option for remote execution of functionality due to its features like ubiquity, independence of operating system and programming language. Thus, web 
services and service-oriented computing provide a wellestablished infrastructure which is widely accepted for supporting agent interactions using XML and HTTP interfaces in multi-agent manufacturing systems.

\section{Complex systems}

A complex system consists of a large number of interacting components whose collective activity is nonlinear with interdependency between components. Hsu et al. (2016) presented a study to understand the complexity in selection of project team member using agent-based modelling. Agent technologies conceptualise the complex systems as consisting of independent components which act, learn or evolve to interact with their surroundings. This conceptualisation includes the computer simulations of the system's operation and behaviours and design of control through agent concepts (Luck et al. 2005). Thus, agent technologies give a proper way to handle increasing complexity in the modern manufacturing systems.

\section{Brief review of ISM methodology}

Interpretive structural modelling has been used by many authors and researchers to analyse the relationships between drivers/enablers for developing more understanding about the systems under consideration. The studies used ISM approach in different applications, are as follows: such as, Raj et al. (2008) presented a study to understand the mutual interrelationships between enablers of FMS and find drive and dependent enablers of FMS. Jadhav et al. (2014) developed a framework for lean implementation using interpretive structural modelling by identifying interrelationships between lean practice bundles. Further, Jadhav et al. (2015a) proposed a road map for successful implementation of JIT production using ISM approach by tackling different barriers in it. Kumar et al. (2013) developed structural model for effective customer involvement in implementation of green supply chain using ISM approach, while Diabat and Govindan (2011) developed a model for the drivers of green supply chain management using ISM framework. Satapathy and Mishra (2013) designed a customer-based systematic framework for Indian electricity industry using quality function deployment (QFD) by measuring service quality using artificial neural network (ANN) and also used ISM approach for finding the interrelationships between design requirements of electricity industry. Jadhav et al. (2015b) proposed a roadmap for lean implementation in Indian automotive component manufacturing industry by comparing ISM model and United Nations Industrial Development Organization (UNIDO) - Automotive Component Manufacturers Association of India (ACMA) model. Bhanot et al. (2017) presented a study that aims to strengthen drivers and mitigate the barriers of sustainable manufacturing using an integrated approach of decision-making trial and evaluation laboratory approach, maximum mean de-entropy algorithm, structural equation modelling and interpretive structural modelling. Chang et al. (2013) presented a research for finding key agile factors to introduce new product in mass production using hybrid approach of ISM and analytical network process (ANP). ISM was used to identify and analyse interrelationships between the agile factors, while ANP was employed to rank the importance of all factors. To analyse the risks in perishable food supply chain and to determine the most effective risk mitigation strategies, Prakash et al. (2017) described a methodology using ISM. Through this methodology all types of involved risks in this supply chain are modelled. Mannan et al. (2016) presented a study to analyse the critical factors using ISM approach for integrating sustainability with innovation considering Indian manufacturing SMEs. Agi and Nishant (2017) discussed a study on understanding the prominent factors on the implementation of green supply chain management practices and analysed the interrelations between these factors using ISM approach. Hence, ISM approach has been adopted by the researchers in several areas, but the analysis of drivers of agent technology using ISM methodology has not been investigated yet.

After scanning the related literature, it can be pointed out that the analysis of interrelationships between the drivers of agent-based manufacturing systems is yet to be discussed. Therefore, in this research, the interactions between critical drivers of agent technology have been analysed for a manufacturing system of an Indian steering wheel manufacturing company using ISM approach.

\section{Development of ISM methodology for implementation of agent technology in manufacturing system}

ISM methodology is used as a communication tool in the complex systems to manage decision-making. The management of a manufacturing system involves several elements associated with physical components and decision-making which complicates the system's structure. It becomes difficult to handle such type of system which does not describe its structure clearly. Hence, it is required to develop a methodology that can identify interrelationship among various elements in the system. Thus, ISM is a learning process in which a set of related components are interacted and organised into a comprehensive systemic model (Warfield 1974; Sage 1977).

ISM is a type of group learning process in which a group of people, they may be the experts of the particular field or the analyst of that particular problem, sit and decide whether and how the drivers are related through 
their judgment and thus make it an interpretive technique. There exist some interrelationships between CDs of AT in terms of driving and dependence power. The management should know these relationships of CDs in order to implement AT in a manufacturing system effectively. Hence, ISM methodology is adopted to know these interrelationships of CDs and develop a structural model of CDs. ISM approach involves following steps. The flow chart of ISM methodology is shown in Fig. 1.

Step 1 The CDs affecting the implementation of AT for a manufacturing system of an Indian steering wheel manufacturing company ' $S$ ' are listed. After this, a contextual relationship is developed for each pair of CDs

Step 2 A structural self-interaction matrix (SSIM) is developed for the CDs, which indicates pairwise interactions between CDs of AT

Step 3 A reachability matrix is developed from the SSIM

Step 4 The reachability matrix is partitioned into different levels

Step 5 The reachability matrix is now converted into conical matrix

Step 6 Based on the above relationships, a structural model for CDs is developed

Step 7 Check conceptual inconsistency in the structural model for CDs and incorporate necessary alterations

\section{Application of ISM methodology for the Indian steering wheel manufacturing company}

The ISM methodology has been applied in an Indian steering wheel manufacturing company ' $S$ ' to develop structural model of CDs of AT. The company 'S' under study produces steering wheels in northern India, and it is one of the firsttier suppliers to the automobile company in steering wheel supplies. Since the growing of automobile companies has increased the requirement of such auto part supplies, the company ' $\mathrm{S}$ ' was deciding technological advancement in its manufacturing system to improve overall production effectiveness as the existing production system has various quality issues, not able to meet customer priorities and due dates. Therefore, the management of the company ' $\mathrm{S}$ ' has decided to adopt ISM methodology to find interrelationships between CDs for AT implementation in its manufacturing system. The ISM methodology for this research study is explained in detail as follows:

\section{Identification of critical drivers}

In order to find the relevant CDs of AT in the company ' $\mathrm{S}$ ', extensive discussions were carried out with the top management consisting of general manager and managers and technical team consisting of senior engineers and engineers of the company ' $\mathrm{S}$ ' and two academic experts. The discussion includes several brainstorming sessions which concluded 7
Fig. 1 Flow chart of ISM methodology

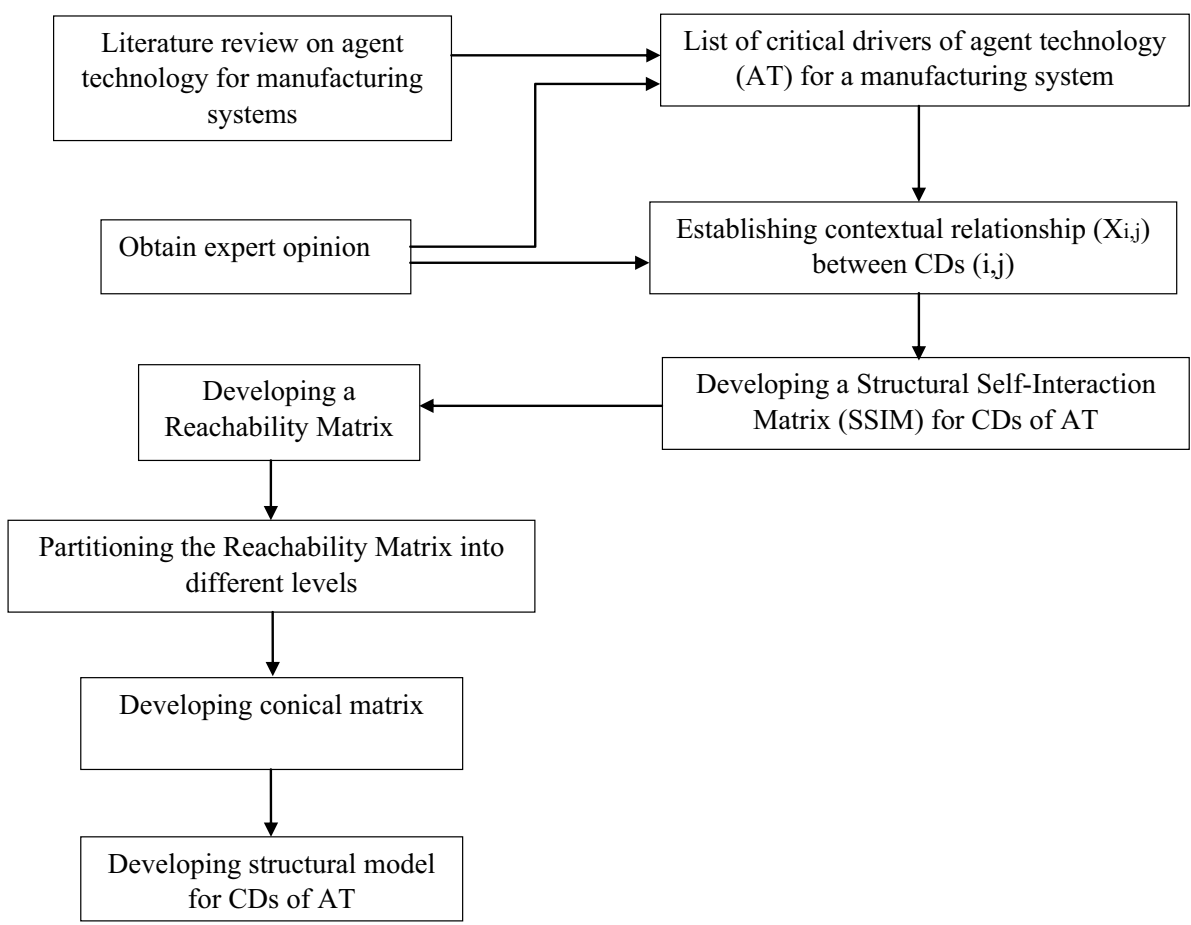


CDs of AT mentioned in Table 1 and relevant to company ' $\mathrm{S}$ ' for AT implementation.

\section{Development of SSIM}

The contextual relationships are developed among the CDs in order to make the SSIM based on pairwise comparison of CDs for a manufacturing system of the company ' $\mathrm{S}$ '. The SSIM was discussed in the decision-making team which consists of six experts to achieve the consensus. SSIM has been finalised based on the responses of six experts, and it is presented in Table 2.

For examining different CDs of AT, "leads to" type relationship is adopted. It means that one driver that may be termed as ' $\mathrm{i}$ ' leads to ' $\mathrm{j}$ ' which is the other driver. The following four symbols have been used to denote the direction of relationship between critical drivers ( $i$ and $j$ ):

$\mathrm{V}$-driver i will lead to achieve driver $\mathrm{j}$;

A-driver $\mathrm{j}$ will lead to achieve driver $\mathrm{i}$;

$\mathrm{X}$ - drivers $\mathrm{i}$ and $\mathrm{j}$ will lead to achieve each other; and

$\mathrm{O}-$ drivers $\mathrm{j}$ and $\mathrm{i}$ are unrelated.

\section{Developing reachability matrix (RM)}

The SSIM converts into a binary matrix, called RM by replacing $\mathrm{V}, \mathrm{A}, \mathrm{X}$ and $\mathrm{O}$ by 1 and 0 as per given case. The substitution of 1 and 0 is as per the following rules (Soni and Kodali 2016):
- If $(i, j)$ entry in SSIM is $V$, then $(i, j)$ entry in RM becomes 1 and $(j, i)$ entry becomes 0 ;

- If $(i, j)$ entry in SSIM is $A$, then $(i, j)$ entry in RM becomes 0 and $(j, i)$ entry becomes 1 ;

- If $(i, j)$ entry in SSIM is $X$, then $(i, j)$ entry in RM becomes 1 and $(j, i)$ entry also becomes 1 ;

- If $(i, j)$ entry in SSIM is O, then ( $i, j$ ) entry in RM becomes 0 and $(j, i)$ entry also becomes 0 .

Based on the above rules, the reachability matrix is developed and shown in Table 3.

\section{Developing level partitions}

Now further for another step of ISM technique in which the reachability and antecedent set for each of the critical driver from the final reachability matrix are obtained. The reachability set is composed of the element itself and the other element which it may affect; on the other hand, the antecedent set consists of the element itself and the other element which may affect it. For acquiring the top level hierarchy in ISM model, the element in the reachability set and intersection set should be same where intersection set is composed of the intersection of reachability set and antecedent set. The top level element will not lead to achieve or impact any other element above their own level in the hierarchy, and thus, once they are obtained, they will be discarded from the set of other elements (Table 4). Similarly, through series of iterations, the other levels of ISM hierarchy are found out.

Table 1 Critical drivers of agent technology

\begin{tabular}{ll}
\hline Drivers & Sources \\
\hline Semantic Web (1) & Berners-Lee et al. (2001), Luck et al. (2005), García-Sánchez et al. (2009) \\
Grid Computing (2) & Foster and Kesselman (2004), Blatecky (2002), Luck et al. (2005), Khan et al. \\
& (2017), Garg et al. (2010), Yang et al. (2016) \\
Peer-to-Peer Computing (3) & Milojicic et al. (2002), Purvis et al. (2003), Luck et al. (2005) \\
Ambient Intelligence (4) & Sanders and Tewkesbury (2009), Luck et al. (2005) \\
Self-System and Autonomic Computing (5) & Luck et al. (2005), Barbosa et al. (2015), Madureira et al. (2014) \\
Web Services and Service-Oriented Computing (6) & Booth et al. (2004), Luck et al. (2005), Lyell et al. (2003), Maamar et al. (2003) \\
Complex Systems (7) & Hsu et al. (2016), Luck et al. (2005) \\
\hline
\end{tabular}

Table 2 Structural SelfInteraction Matrix (SSIM)

\begin{tabular}{llllllll}
\hline Elements & 7 & 6 & 5 & 4 & 3 & 2 & 1 \\
\hline 1. Semantic Web & V & X & O & O & V & V & X \\
2. Grid Computing & V & X & O & V & A & X & \\
3. Peer-to-Peer Computing & V & A & A & V & X & & \\
4. Ambient Intelligence & X & A & X & X & & & \\
5. Self-System and Autonomic Computing & V & A & X & & & & \\
6. Web Services and Service-Oriented Computing & V & X & & & & & \\
7. Complex Systems & X & & & & & & \\
\hline
\end{tabular}


Table 3 Reachability Matrix

\begin{tabular}{llllllll}
\hline Elements & 1 & 2 & 3 & 4 & 5 & 6 & 7 \\
\hline 1. Semantic Web & 1 & 1 & 1 & 0 & 0 & 1 & 1 \\
2. Grid Computing & 0 & 1 & 0 & 1 & 0 & 1 & 1 \\
3. Peer-to-Peer Computing & 0 & 1 & 1 & 1 & 0 & 0 & 1 \\
4. Ambient Intelligence & 0 & 0 & 0 & 1 & 1 & 0 & 1 \\
5. Self-System and Autonomic Computing & 0 & 0 & 1 & 1 & 1 & 0 & 1 \\
6. Web Services and Service-Oriented Computing & 1 & 1 & 1 & 1 & 1 & 1 & 1 \\
7. Complex Systems & 0 & 0 & 0 & 1 & 0 & 0 & 1 \\
\hline
\end{tabular}

Table 4 Level partitions-I iteration

\begin{tabular}{|c|c|c|c|c|}
\hline Elements & $\begin{array}{l}\text { Reachability } \\
\text { Set }\end{array}$ & Antecedent Set & $\begin{array}{l}\text { Intersection } \\
\text { Set }\end{array}$ & Levels \\
\hline 1 & $1,2,3,6,7$ & 1,6 & 1,6 & \\
\hline 2 & $2,4,6,7$ & $1,2,3,6$ & 2,6 & \\
\hline 3 & $2,3,4,7$ & $1,3,5,6$ & 3 & \\
\hline 4 & $4,5,7$ & $2,3,4,5,6,7$ & $4,5,7$ & I \\
\hline 5 & $3,4,5,7$ & $4,5,6$ & 4,5 & \\
\hline 6 & $\begin{array}{l}1,2,3,4,5 \\
\quad 6,7\end{array}$ & $1,2,6$ & $1,2,6$ & \\
\hline 7 & 4,7 & $\begin{array}{c}1,2,3,4,5 \\
6,7\end{array}$ & 4,7 & I \\
\hline
\end{tabular}

Table 5 Level partitions-final iteration

\begin{tabular}{lllll}
\hline Elements & $\begin{array}{l}\text { Reachability } \\
\text { Set }\end{array}$ & Antecedent Set & $\begin{array}{l}\text { Intersection } \\
\text { Set }\end{array}$ & Levels \\
\hline 1 & $1,2,3,6,7$ & 1,6 & 1,6 & IV \\
2 & $2,4,6,7$ & $1,2,3,6$ & 2,6 & II \\
3 & $2,3,4,7$ & $1,3,5,6$ & 3 & III \\
4 & $4,5,7$ & $2,3,4,5,6,7$ & $4,5,7$ & I \\
5 & $3,4,5,7$ & $4,5,6$ & 4,5 & IV \\
6 & $1,2,3,4,5$, & $1,2,6$ & $1,2,6$ & V \\
7 & 6,7 & & & \\
7 & 4,7 & $1,2,3,4,5$, & 4,7 & I \\
& \multicolumn{5}{c}{6,7} \\
\hline
\end{tabular}

The results for iteration II to $\mathrm{V}$ are summarised in Table 5. The obtained levels of ISM technique are now used for the construction of the ISM model.

\section{Conical matrix}

For developing a conical matrix (in Table 6), the variables are clustered in the same level across row and column of final reachability matrix. The dependence power of critical driver is defined by summing up the number of ones in the column, and likewise the driving power is obtained by adding the number of ones in the row. Moving ahead rank of driving power and dependence power is obtained of critical drivers having maximum sum in the rows and column accordingly.

\section{Development of structural model for CDs}

The development of structural model for CDs for an Indian steering wheel manufacturing company ' $S$ ' involves ISM hierarchical level in which the CDs are placed. Level I of structural model is at the top, and level $\mathrm{V}$ is at the bottom. Critical driver 'web services and service-oriented computing' (6) coming in the level $\mathrm{V}$ and having the largest driving power placed at the lowest level of structural model similarly critical driver ambient intelligence (4) and complex systems (7) coming under level I and having highest dependencies

Table 6 Conical Matrix

\begin{tabular}{llllllllll}
\hline Critical Drivers & 4 & 7 & 2 & 3 & 1 & 5 & 6 & Driving Power & Rank \\
\hline 4 & 1 & 1 & 0 & 0 & 0 & 1 & 0 & 3 & IV \\
7 & 1 & 1 & 0 & 0 & 0 & 0 & 0 & 2 & V \\
2 & 1 & 1 & 1 & 0 & 0 & 0 & 1 & 4 & III \\
3 & 1 & 1 & 1 & 0 & 0 & 0 & 0 & 4 & III \\
1 & 0 & 1 & 1 & 1 & 1 & 0 & 1 & 5 & II \\
5 & 1 & 1 & 0 & 1 & 0 & 1 & 0 & 4 & II \\
6 & 1 & 1 & 1 & 1 & 1 & 1 & 1 & 7 & I \\
Dependence power & 6 & 7 & 4 & 4 & 2 & 3 & 3 & & \\
Rank & II & I & III & III & V & IV & IV & & \\
\hline
\end{tabular}


are at the top level, and accordingly, whole structural model for CDs is developed in Fig. 2.

\section{MICMAC analysis}

The purpose of MICMAC analysis (Mandal and Deshmukh 1994) for this study is to analyse the CDs of AT according to their driving and dependence power in a manufacturing system of the company ' $S$ '. The CDs are classified in four categories based on their driving power and dependence power.

I. Autonomous drivers These have weak driving and weak dependence power. These drivers are relatively discarded from the ISM implementation process.

II. Dependent drivers It consists of dependent critical drivers that have weak driving power and strong dependence. In this category of drivers, two critical drivers (i.e. ambient intelligence and complex systems) are placed.

III. Linkage drivers This category of drivers includes strong driving power as well as strong dependence power. Two critical drivers (i.e. grid computing and peer-to-peer computing) are found in this category.

IV. Independent drivers These types of drivers have strong driving power and weak dependence power. These are generally called as 'key drivers'. Three critical drivers (i.e. semantic web, web services and service-oriented computing and self-systems and autonomic computing) are found in this type of drivers.

The driving and dependence power of critical drivers are given in conical matrix as in Table 6. After doing MICMAC analysis, the driving-dependence power diagram is drawn in Fig. 3. This diagram is divided into four categories. First category includes 'autonomous drivers', second contains 'dependent drivers', third comprises of 'linkage drivers', and 'independent drivers' are in fourth category. From Table 6, it is observed that critical driver (6) has driving power of 7 and dependence power of 3. Hence, in Fig. 3, it is placed corresponding to driving power of 7 and dependence power of 3 which is in part IV. Similarly other drivers are placed in this diagram.

\section{Finding and discussion}

The concept of agent technology (AT) is a very important topic for the practitioners and researchers. Implementing AT in a manufacturing system is tough and challenging to adopt. A group of CDs can make easy to accomplish successful employment of AT. It needs to investigate the effect of these CDs and to find the interrelationships between them during AT implementation. Hence, the Indian steering wheel manufacturing company ' $S$ ' needs to define most effective driver for AT employment.
Fig. 2 Structural model for CDs of AT for an Indian steering wheel manufacturing company 'S'

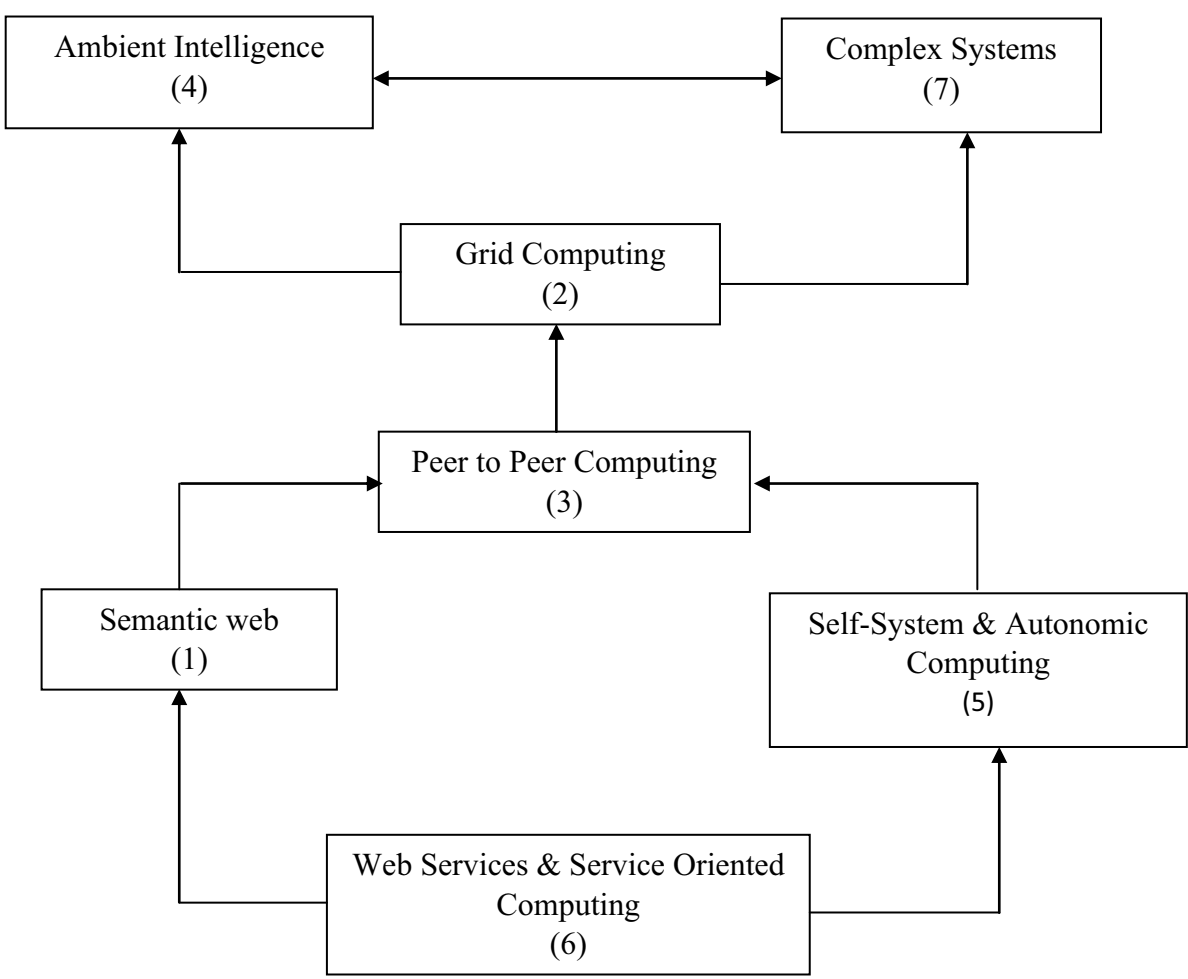




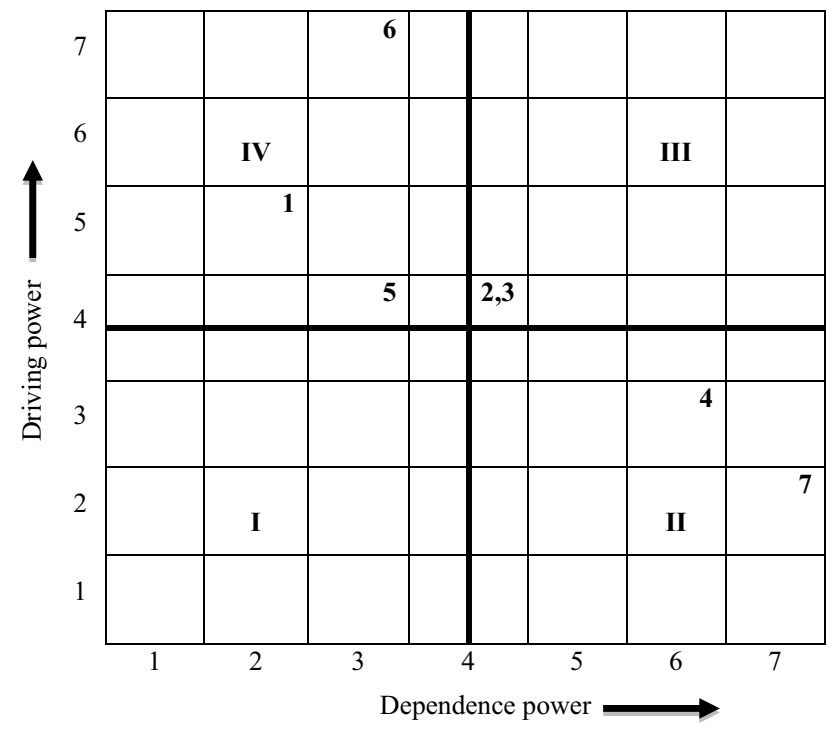

Fig. 3 Driving-dependence power diagram of $\mathrm{CDs}$ for an Indian steering wheel manufacturing company ' $\mathrm{S}$ '

This study aims to find and define interrelationships among all identified CDs of AT and further to analyse drive and dependence power of those CDs for successful AT implementation in a manufacturing system for the manufacturing company ' $\mathrm{S}$ '. To achieve these goals, ISM methodology has been deployed in order to understand the relationships between CDs so that the manufacturing company ' $\mathrm{S}$ ' may give more stress on those $\mathrm{CDs}$ which are more influential for AT employment. It will help to deal with uncertainty in the manufacturing system which improves its flexibility, and simultaneously, customer satisfaction will also be achieved.

In this study, ISM-MICMAC approach is used since binary relationships among identified CDs are being done by ISM while MICMAC approach describes sensitive analysis of driving and dependence behaviour of CDs. It has been observed from structural model for CDs (Fig. 2) that the ambient intelligence and complex systems are at the first (top) level. The ambient intelligence needs agents to interact with other agents to fulfil their goals, and complex systems involve complexity of modern software systems which can only be tackled by agents in the manufacturing system. Hence, lack of these two drivers leads to lack of grid computing at level 2 and lack of peer-to-peer computing at level 3. Level 4 constitutes semantic web and self-system and autonomic computing in AT implementation in a manufacturing system. Finally, web services and service-oriented computing form level 5 which is bottom level of ISM model.

Another aim of this research was to analyse the driving and dependence power of CDs that affect AT employment in a manufacturing system by MICMAC analysis. The drivers are classified into four categories (Fig. 3) in MICMAC analysis.
The driving-dependence power diagram (Fig. 3) shows that no CDs are found in the category of autonomous drivers. It concludes that all the CDs influence the AT implementation in a manufacturing system for the Indian steering wheel manufacturing company ' $\mathrm{S}$ '. The ambient intelligence and complex systems are weak CDs but strong dependent on other drivers (Fig. 3-category II). These drivers are considered as important because these are shown in top level of structural model. Their strong dependencies indicate that they require other CDs (Fig. 3-category IV) to maximise the effect of these CDs in AT. Therefore, the management of the company ' $S$ ' should give high importance to these drivers. Two CDs, i.e. grid computing and peer-to-peer computing, are strong drivers and strong dependent on others (Fig. 3-category III). Any change in these drivers will affect other drivers and also give a feedback to them. Figure 3-category IV—indicates the 'semantic web', 'self-system and autonomic computing' and 'web services and service-oriented computing' are strong driver and weak dependent on others. These CDs help to attain other drivers that are at the top level of structural model. It concludes that the management of the company ' $S$ ' needs focus on these drivers more cautiously.

\section{Implications of the research}

The important implications of this research are as follows:

- In this study, no CD has been identified which has a weak driving and weak dependence power. It concludes that all CDs would participate in the implementation of AT in a manufacturing system for the manufacturing company 'S'.

- In the present paper, an effort has been made to find the CDs for AT implementation in a manufacturing system for the Indian steering wheel manufacturing company ' $S$ '. The presented structural model for CDs for the company ' $\mathrm{S}$ ' would assist to manufacturing firms and research community to understand the interrelationship among CDs of AT and accordingly implement in their problems. In this context this study assumes significant contribution.

- The driving-dependence power diagram indicates the interdependency and the relative importance of the CDs of AT in a manufacturing system. This would help in making decisions and practicing of implementation of agent technology in the manufacturing company ' $\mathrm{S}$ '.

\section{Conclusion}

The customer-driven market has forced the manufacturing industries to adopt technological advancement. This has introduced agent technology which provides the flexibility 
to the manufacturing system to deal with complexity and uncertainty. Though, a few research articles are available on different CDs of AT, no research study available on the classification of the drivers affecting AT and their relationships according to ISM-MICMAC approach.

The management of an Indian steering wheel manufacturing company ' $\mathrm{S}$ ' was planning to implement $\mathrm{AT}$ in its manufacturing system for making it more technological advanced. To make easy implementation of AT in the manufacturing system for the manufacturing company ' $\mathrm{S}$ ', this paper develops structural model which provides the identification of CDs affecting AT and their interrelationships. In this paper, 7 CDs affecting implementation of AT are identified and classified into four categories in an Indian manufacturing company ' $\mathrm{S}$ ', with taken inputs from literature reviews and through discussions held with managers, engineers and academicians. These CDs can be considered for a specific Indian manufacturing company with some CDs may be added or removed from the proposed list of CDs for successful implementation of AT. The behaviour of each $\mathrm{CD}$ has been analysed by MICMAC analysis which provides the category of CDs. The major finding of this study is that ambient intelligence and complex systems are the most influential CDs which lead to increase the effect of other drivers. Another finding is that management of the company 'S' should focus on 'semantic web', 'self-system and autonomic computing' and 'web services and service-oriented computing' CDs more cautiously due to strong driving and weak dependence behaviour of these drivers.

Further research can be suggested to develop structural model for CDs of AT using ISM with fuzzy logic approach. ISM-MICMAC methodology provides binary relationships, but fuzzy MICMAC approach will increase the sensitivity in the system.

Open Access This article is distributed under the terms of the Creative Commons Attribution 4.0 International License (http://creativeco mmons.org/licenses/by/4.0/), which permits unrestricted use, distribution, and reproduction in any medium, provided you give appropriate credit to the original author(s) and the source, provide a link to the Creative Commons license, and indicate if changes were made.

\section{References}

Agi MA, Nishant R (2017) Understanding influential factors on implementing green supply chain management practices: an interpretive structural modelling analysis. J Environ Manag 188:351-363

Alotaibi A, Lohse N, Tuong Manh V (2016) Dynamic agent-based biobjective robustness for tardiness and energy in a dynamic flexible job Shop. Procedia CIRP 57:728-733

Antzoulatos N, Castro E, de Silva L, Rocha AD, Ratchev S, Barata J (2017) A multi-agent framework for capability-based reconfiguration of industrial assembly systems. Int J Prod Res 55(10):2950-2960
Babayan A, He D (2004) A distributed scheduling methodology for a two-machine flowshop using cooperative interaction via multiple coupling agents. Int J Prod Res 42(4):777-7104

Barbosa J, Leitão P, Adam E, Trentesaux D (2015) Dynamic selforganization in holonic multi-agent manufacturing systems: the ADACOR evolution. Comput Ind 66:99-111

Berners-Lee T, Hendler J, Lassila O (2001) The semantic web. Sci Am 284(5):28-37

Bhanot N, Venkateswara Rao P, Deshmukh SG (2017) An integrated approach for analysing the enablers and barriers of sustainable manufacturing. J Clean Prod 142:4412-4439

Blatecky A (2002) Grid computing. EDUCAUSE Center Appl Res 17:419-423

Booth D, Haas H, McCabe F, Newcomer E, Champion M, Ferris C, Orchard D (2004) Web services architecture, W3C Working Group Note 11 February. http://www.w3.org/TR/ws-arch/

Chang A-Y, Kuo-Jen H, Hong Y-L (2013) An ISM-ANP approach to identifying key agile factors in launching a new product into mass production. Int J Prod Res 51(2):582-597

Chryssolouris G (2006) Manufacturing systems: theory and practice, 2nd edn. Springer, New York

Diabat A, Govindan K (2011) An analysis of the drivers affecting the implementation of green supply chain management. Resour Conserv Recycl 55(6):659-667

D'Souza DE, Williams FP (2000) Toward a taxonomy of manufacturing flexibility dimensions. J Oper Manag 18(5):577-593

Erol R, Sahin C, Baykasoglu A, Kaplanoglu V (2012) A multi-agent based approach to dynamic scheduling of machines and automated guided vehicles in manufacturing systems. Appl Soft Comput 12(6): 1720-1732

Foster I, Kesselman C (2004) The grid 2-blueprint for a new computing infrastructure, vol 2. Elsevier, Amsterdam

García-Sánchez F, Valencia-García R, Martínez-Béjar R, FernándezBreis JT (2009) An ontology, intelligent agent-based framework for the provision of semantic web services. Expert Syst Appl 36(2):3167-3187

Garg SK, Buyya R, Siegel HJ (2010) Time and cost trade-off management for scheduling parallel applications on utility grids. Future Gener Comput Syst 26(8):1344-1355

Hsu S-C, Weng K-W, Cui Q, Rand W (2016) Understanding the complexity of project team member selection through agent-based modeling. Int J Project Manage 34(1):82-93

Jadhav JR, Mantha SS, Rane SB (2014) Development of framework for sustainable lean implementation: an ISM approach. J Ind Eng Int 10(3):72

Jadhav JR, Mantha SS, Rane SB (2015a) Analysis of interactions among the barriers to JIT production: interpretive structural modelling approach. J Ind Eng Int 11(3):331-352

Jadhav JR, Mantha SS, Rane SB (2015b) Roadmap for Lean implementation in Indian automotive component manufacturing industry: comparative study of UNIDO Model and ISM Model. J Ind Eng Int 11(2):179-198

Khan Sumair, Nazir Babar, Khan Iftikhar Ahmed, Shashirband Shahaboddin, Chronopoulos Anthony T (2017) Load balancing in grid computing: taxonomy, trends and opportunities. J Netw Comput Appl 88:99-111

Kumar S, Luthra S, Haleem A (2013) Customer involvement in greening the supply chain: an interpretive structural modeling methodology. J Ind Eng Int 9(1):6

Luck M, McBurney P, Shehory O, Willmott S (2005) Agent technology: computing as interaction (a roadmap for agent based computing). University of Southampton

Lyell M, Rosen L, Casigni-Simkins M, Norris D (2003) On software agents and web services: usage and design concepts and issues. In: Proceedings of the AAMAS2003 workshop on web services and agent-based engineering (WSABE2003) 
Maamar Z, Sheng QZ, Benatallah B (2003) Interleaving web services composition and execution using software agents and delegation. In: Proceedings of the AAMAS2003 workshop on web services and agent-based engineering (WSABE2003)

Madureira A, Pereira I, Pereira P, Abraham A (2014) Negotiation mechanism for self-organized scheduling system with collective intelligence. Neurocomputing 132:97-110

Mandal A, Deshmukh SG (1994) Vendor selection using interpretive structural modelling (ISM). Int J Oper Prod Manag 14(6):52-59

Mannan B, Khurana S, Haleem A (2016) Modeling of critical factors for integrating sustainability with innovation for Indian small-and medium-scale manufacturing enterprises: an ISM and MICMAC approach. Cogent Bus Manag 3(1):1140318

Milojicic DS, Kalogeraki V, Lukose R, Nagaraja K, Pruyne J, Richard B, Rollins S, Xu Z (2002) Peer-to-peer computing. HP Technical report HPL-2002-57

Narasimhan R, Talluri S, Das A (2004) Exploring flexibility and execution competencies of manufacturing firms. J Oper Manag 22(1):91-106

Nouri HE, Driss OB, Ghédira K (2016) Simultaneous scheduling of machines and transport robots in flexible job shop environment using hybrid metaheuristics based on clustered holonic multiagent model. Comput Ind Eng 102:488-501

Nouri HE, Driss OB, Ghédira K (2018) Solving the flexible job shop problem by hybrid metaheuristics-based multiagent model. J Ind Eng Int 14(1):1-14

Papakostas N, Papachatzakis P, Xanthakis V, Mourtzis D, Chryssolouris G (2011) An Approach to Operational Aircraft Maintenance Planning. Int J Dec Support Syst 48(4):604-612

Prakash S, Soni G, Rathore APS, Singh S (2017) Risk analysis and mitigation for perishable food supply chain: a case of dairy industry. Benchmark Int J 24(1):2-23

Purvis M, Nowostawski M, Cranefield S, Oliveira M (2003) Multiagent interaction technology for peer-to-peer computing in electronic trading environments. In: International workshop on agents and P2P computing. Springer, Berlin, pp 150-161

Raj T, Shankar R, Suhaib M (2008) An ISM approach for modelling the enablers of flexible manufacturing system: the case for India. Int J Prod Res 46(24):6883-6912

Rezki N, Kazar O, Mouss LH, Kahloul L, Rezki D (2016) On the use of multi-agent systems for the monitoring of industrial systems. J Ind Eng Int 12(1):111-118

Robinson DC, Sanders DA, Mazharsolook E (2015) Ambient intelligence for optimal manufacturing and energy efficiency. Assembly Autom 35(3):234-248
Sage A (1977) Interpretive structural modeling: methodology for largescale systems. McGraw-Hill, New York, pp 91-164

Sanders DA, Tewkesbury GE (2009) A pointer device for TFT display screens that determines position by detecting colours on the display using a colour sensor and an artificial neural network. Displays 30(2):84-96

Satapathy S, Mishra P (2013) A customer oriented systematic framework to extract business strategy in Indian electricity services. J Ind Eng Int 9(1):33

Seebacher G, Winkler H (2014) Evaluating flexibility in discrete manufacturing based on performance and efficiency. Int J Prod Econ 153:340-351

Shi D, Daniels RL (2003) A survey of manufacturing flexibility: implications for e-business flexibility. IBM Syst J 42(3):414-427

Soni G, Kodali R (2016) Interpretive structural modeling and path analysis for proposed framework of lean supply chain in Indian manufacturing industry. J Ind Prod Eng 33(8):501-515

Urtasun-Alonso A, Larraza-Kintana M, García-Olaverri C, HuertaArribas E (2014) Manufacturing flexibility and advanced human resource management practices. Prod Plan Control 25(4):303-317

Warfield JN (1974) Developing interconnection matrices in structural modeling. IEEE Trans Syst Man Cybern 1:81-87

Weng W, Fujimura S (2010) Flexible flow shop scheduling by intelligent multi-agents. In: Eighth ACIS international conference on software engineering research, management and applications (SERA). IEEE, pp 113-120

Winkler H, Seebacher G (2011) The flexible design of supply chains. In: International supply chain management and collaboration practices. EUL, Cologne, pp 213-231

Wooldridge M (2002) An introduction to multi agent systems. Wiley, Chichester

Yang C, Jiang B, Ono I, Kurahashi S, Terano T (2016) A grid based simulation environment for agent-based models with vast parameter spaces. Cluster Comput 19(1):183-195

Yue-wen F, Feng-Xing Z, Xiao-Hong X, Qing-Zhu C, Jia-hua W (2011) Hybrid flow-shop scheduling method based on multi-agent particle swarm optimization. In: IEEE international conference on information and automation (ICIA). IEEE, pp 755-759

Zhang J, Wang X (2016) Multi-agent-based hierarchical collaborative scheduling in re-entrant manufacturing systems. Int J Prod Res 54(23):7043-7059

Zhang Q, Vonderembse MA, Lim J-S (2003) Manufacturing flexibility: defining and analyzing relationships among competence, capability, and customer satisfaction. J Oper Manag 21(2):173-191 